\title{
NX Stage Finding
}

National Cancer Institute

\section{Source}

National Cancer Institute. NX Stage Finding. NCI Thesaurus. Code C48718.

A regional lymph node TNM finding indicating that the status of regional lymph nodes cannot be assessed. 